\title{
6
}

\section{FRASEOLOGISMOS NA ÁREA SEMÂNTICA DO CORPO HUMANO A PARTIR DE DADOS GEOLINGUÍSTICOS: O QUE REVELAM OS DADOS DO NORTE E DO SUL DO BRASIL ${ }^{1}$}

\author{
PHRASEOLOGISMS IN THE SEMANTIC AREA OF THE \\ HUMAN BODY FROM GEOLINGUISTIC DATA: WHAT IS \\ REPORTED BY THE NORTH AND SOUTH DATA OF BRAZIL
}

\author{
Juliany Fraide Nunes ${ }^{2}$ \\ Aparecida Negri Isquerdo ${ }^{3}$ \\ Elizabete Aparecida Marques ${ }^{4}$ \\ Universidade Federal do Mato Grosso do Sul - UFMS
}

Resumo: Este trabalho discute expressões fixas documentadas pelo Projeto ALiB (Atlas Linguístico do Brasil) para nomear partes do corpo humano nas regiões Norte e Sul do Brasil, dados inéditos que compõem o corpus do Projeto VALEXTRA que foram analisados segundo os pressupostos teóricos da Fraseologia, particularmente a posição teórica de Gross (1996) e de Mejri (1997). O estudo demonstrou que dados orais também se configuram como fontes significativas de fraseologismos, conclusão que instiga novos estudos na área.

Palavras-chave: corpo humano; unidades fraseológicas; Norte; Sul; Brasil.

1 Uma primeira versão deste trabalho foi apresentada por Nunes e Isquerdo no IV Congresso Internacional de Fraseologia e Paremiologia e [do] III Congresso Brasileiro de Fraseologia, realizado na UNESP/São José do Rio Preto/SP, em março de 2016. Para este trabalho, com a participação de Marques, o corpus foi ampliado e a análise aprofundada, incluindo novos enfoques.

2 Professora temporária da UFMS. Membro do Projeto ALiB. E-mail: julianyfraide@gmail.com.

3 Bolsista de Produtividade do CNPq. Membro do Projeto CAPES-COFECUB 838/15. E-mail: aparecida.isquerdo@gmail.com

$4 \quad$ Membro do Projeto CAPES-COFECUB 838/15. E-mail: eamarques@hotmail.com. 
Abstract: This paper discusses idioms documented by ALiB Project (Linguistic Atlas of Brazil) to name parts of the human body in the North and South Regions of Brazil, unpublished data that compose the corpus of the VALEXTRA Project that were analyzed according to the theoretical presuppositions of Phraseology, particularly the theoretical position of Gross (1996) and Mejri (1997). The study showed that oral data also constitute significant sources of phraseologisms, a conclusion that instigates new studies in the area.

Keywords: human body; phraseological units; North; South; Brazil.

\section{CONSIDERAÇÕES INICIAIS}

Embora os estudos fraseológicos se voltem prioritariamente para unidades léxicas veiculadas pela língua escrita, língua geral e de especialidade, pesquisas na área têm também se voltado para recortes lexicais oriundos da língua oral e demonstrado resultados relevantes. Nesse contexto, situa-se o Projeto VALEXTRA ${ }^{5}$ que tem como objeto de pesquisa as expressões fixas no português brasileiro a partir dos dados geolinguísticos do Projeto ALiB. Partese do pressuposto que "[...] les expressions figées sont des unités de langue (signes codés), elles apparaissent et se figent dans les discours, de répétition en répétition, comme les néologismes. [...]; l'étude du figement et de la néologie lexicale attire l'attention sur l'interaction entre langue et discours, et manifeste le rôle de la «masse parlante» dans la constitution des unités linguistiques et des règles de leur usage» (MORTUREUX, 2011, p. 111). Este estudo centra-se no estudo de expressões fixas na área semântica do corpo humano auferidas pelo Projeto ALiB nas regiões Norte e Sul do Brasil. Como principal processo de nomeação das partes do corpo humano, situa-se o metafórico, em que os indivíduos se valem de seu conhecimento de mundo para nomear determinados referentes desconhecidos. Assim, partindo do pressuposto da metaforização, este trabalho analisa expressões fixas extraídas do corpus oral do Projeto ALiB, relacionadas à área semântica do corpo humano. Para tanto,

[...] parte-se da hipótese de que muitas expressões metafóricas resultam de analogias entre o corpo humano e outras realidades e essa relação se configura como um universal de caráter extralinguístico condicionado pela universalidade das operações mentais humanas (MARQUES, 2012, p. 334).

5 Projeto vinculado ao convênio CAPES-COFECUB 838/15 que resulta de uma parceria entre a Université Paris 13 e a Universidade Federal da Bahia, com a participação de mais quatro universidades brasileiras: UFMS, UFPA, UFMA e UEL. Esse projeto é coordenado pelo Prof. Dr. Salah Mejri (Université Paris 13) e pela Profa. Dra. Marcela Moura Torres Paim (Universidade Federal da Bahia). 


\section{FRASEOLOGIA: UMA REFLEXÃO SOBRE AS EXPRESSÕES FIXAS}

O léxico de uma língua reflete os fatores sociais, históricos e geográficos relacionados a uma comunidade linguística, evidenciando, também, processos cognitivos do informante empregados ao se comunicar. A partir do ato comunicativo, o indivíduo se inter-relaciona com os demais e demonstra, sobretudo, suas marcas culturais e crenças passadas por seus antepassados que transparecem em suas escolhas, geralmente lexicais, disponíveis no sistema linguístico.

O sistema léxico de uma língua natural é formado por lexia simples, composta e complexa, conforme Pottier (1968). Para o estudioso, a lexia se configura como uma "unidade de comportamento", e é a lexia simples que corresponde a uma unidade lexical, como, por exemplo, cachorro, casa. Já as lexias compostas e complexas são formadas por mais de um item lexical, como guarda-roupa ou chá de cadeira.

Percebe-se nesses dois exemplos que guarda-roupa tem sentido literal, isto é, 'lugar onde se armazena as vestimentas', enquanto chá de cadeira não é um chá feito a partir da cadeira, mas uma forma de comunicar que alguém deixou outra pessoa esperando por muito tempo. Nota-se, pois, que a lexia complexa chá de cadeira tem um sentido figurado, pois as unidades juntas formam um novo sentido não composicional.

Essas unidades formadas por dois ou mais itens lexicais, que em bloco adquirem um sentido que nem sempre é composicional, denomina-se expressão fixa. Biderman argumenta que essas unidades complexas "se caracterizam por ser parte da herança lexical e devem, por conseguinte, ser aprendidas de cor pelos falantes da língua" (BIDERMAN, 1999, p. 93).

Dito isso, este trabalho inscreve-se no âmbito da Fraseologia, concebida aqui como um ramo dos estudos do léxico que se ocupa das unidades léxicas complexas denominadas, também, expressões fixas ou unidades fraseológicas ${ }^{6}$. Mesmo não tendo se debruçado sobre o estudo dessas unidades linguísticas, como afirma Tristá (1988), Charles Bally, no início do século XX, é considerado

6 Unidade fraseológica é um dos termos que tem sido usado como hiperônimo para se referir a uma ampla variedade de fenômenos fraseológicos que, em comum, compartilham duas propriedades essenciais: a polilexicalidade e a fixidez. A fraseóloga espanhola Corpas Pastor (1996) contribuiu para a difusão do termo ao adotar uma concepção ampla de fraseologia que abarca um leque de unidades que, dependendo de suas características e funções, podem ser categorizadas em três esferas: colocações, locuções e enunciados fraseológicos. 
um dos percursores da disciplina ao chamar a atenção para as combinatórias não livres de palavras e ao afirmar que "las combinaciones de palabras presentan diversos grados de cohesión dentro de los límites de dos casos extremos" (TRISTÁ, 1988, p. 2-3). A mesma estudiosa pondera que, embora Bally tenha sido um dos primeiros a apontar o fenômeno linguístico relacionado à fraseologia, a maior contribuição para a sistematização dos estudos fraseológicos adveio da escola russa por meio dos trabalhos, principalmente, de Vinogradov, na década de 40 do século XX.

Mas, afinal, o que é Fraseologia? Tristá entende que "la fraseología constituye una rama especial de la Lingüística, con sus métodos y objetos de estudio" (TRISTÁ, 1988, p. 10). Contudo, como bem indica González Rey (2015), parece não haver, ainda, um consenso entre os pesquisadores se a Fraseologia é um ramo da Lexicologia ou uma disciplina autônoma. Compartilha-se, neste estudo, do ponto de vista de Penadés Martínez (2010), para quem a Fraseologia tem seu objeto de estudo bem definido além de escopo teórico consistente, permitindo alçá-la ao mesmo nível de uma disciplina como a Lexicologia. Irmanada com as demais disciplinas das denominadas "ciências do léxico", os fraseologismos, outro termo hiperonímico para denominar o objeto de estudo da disciplina, podem ser estudados sob diferentes perspectivas teóricas.

Em razão das características dos dados, a vertente francesa dos estudos fraseológicos mostrou-se pertinente para a seleção, a análise e a discussão do material fraseológico extraído do corpus, como é possível observar na sequência deste texto.

O conceito de fixidez é central na perspectiva teórica assumida neste estudo. Ele é vertebral na medida em que as combinatórias não livres da língua são nomeadas mediante a noção de fixidez, uma vez que esta permite dar conta de fenômenos de natureza muito diversa, como bem esclarece Gross (1996, p. 9): “[...] le terme le plus approprié est celui de figement, car il permet de rendre compte à la fois de phénomènes de nature très diverse mais qui ne sont pas indépendants les uns des autres".

Além da fixidez em seus diferentes graus, Gross (1996) aponta onze propriedades que caracterizam as expressões fixas7: a polilexicalidade, a opacidade semântica, o bloqueio das propriedades transformacionais, a não atualização dos elementos, o bloqueio de paradigmas sinonímicos, a não inserção, a desfixidez (defigement), a etimologia e as locuções reduzíveis a

Mejri (1997) utiliza o termo sequência fixa. 
categorias de palavras. Nessa visão do autor francês, inclusive, as lexias compostas são consideradas expressões fixas, pois «un nom composé fonctionne comme un seul bloc du point de vue de ses relations avec le rest de la phrase» (GROSS, 1996, p. 28).

Retomando a fixidez, por ser esta uma das propriedades essenciais das expressões fixas, cabe salientar que, para Gross (1996), as expressões podem apresentar diferentes graus de fixidez, isto é, em uma combinação fixa, os itens lexicais podem encontrar-se unidos de tal maneira que são imutáveis, indissociáveis, convivendo em uma relação de fixidez total, ou apenas um elemento é fixo e o outro poder ser trocado, admitindo-se, portanto, a substituição de um item lexical da combinatória. Nessa perspectiva, Gross (1996) divide as expressões fixas de acordo com o grau de fixidez, de forma que elas podem agrupar-se em torno das expressões com fixidez completa, como, por exemplo, calcanhar de Aquiles e expressões com fixidez de uma parte do grupo nominal, como levar um susto. O pesquisador defende, ainda, que o item fixado, geralmente, é originado de dois processos, o metafórico e o metonímico. Dos dois, o primeiro é bem mais produtivo.

Com base na teoria de Gross (1996), Mejri (1997) também defende que a expressão fixa tem diferentes graus de fixidez que perpassam a linha de um continuum, isto é, cada sequência fixa (termo utilizado pelo autor) traz consigo uma evolução de cristalização ou fixação, pois não é de uma hora para a outra que uma expressão muda o seu caráter de transparência para opacidade semântica. A figura, a seguir, contém as etapas dessa transformação.

Figura 1 - Etapas do processo de fixação (MEJRI, 1997)



Fonte: Mejri (1997, p. 49), figura reproduzida pelas autoras do trabalho. 
A figura mostra que, segundo Mejri (1997), para uma expressão adquirir fixidez total, ela passa por seis etapas:

1) sequência livre, sentido composicional: olho torto

2) sequência fixa, sentido composicional: dente do juízo;

3) sequência fixa, sentido deduzível pelos elementos da sequência: capela do olho;

4) sequência fixa, o sentido é deduzível, a cada vez, a partir do sentido dos elementos e do contexto: perna de baladeira;

5) sequência fixa, o significado é deduzível a partir dos elementos fornecidos pelo contexto: instalação trocada, e

6) sequência fixa, o sentido não é deduzível de seus elementos constituintes: perna de pau.

A partir dessa proposta, nota-se que, quando se analisa uma unidade lexical, não se pode considerar apenas se tratar de uma sequência livre ou de uma sequência fixa, mas sim todas as características de cada etapa e, também, analisar os aspectos que a definem, como proposto por Gross (1996). Mejri (1997, p. 29), por seu turno, define a sequência fixa como "est un syntagme formé conformément à la syntaxe de la langue et qui, une fois réutilizé et entré dans l'usage, sera lui aussi une séquence figée". Para este estudo, foram utilizadas como parâmetro as etapas de fixidez propostas por Mejri (1197) para classificar uma sequência como fixa. Finalizado este tópico, no próximo são discutidos os pressupostos metodológicos que orientam a produção deste trabalho.

\section{PRESSUPOSTOS METODOLÓGICOS}

Como já mencionado, este texto examina material inédito disponível no banco de dados do Projeto ALiB - Atlas linguístico do Brasil, projeto nacional que tem como objetivo mais amplo a documentação da língua portuguesa, modalidade oral, em todo o território brasileiro. Seguindo os parâmetros das pesquisas geolinguísticas, o Projeto ALiB adotou como instrumento de coleta de material linguístico um Questionário Linguístico que reúne três questionários, cada um voltado para um nível distinto da língua: Questionário fonéticofonológico; Questionário Semântico-lexical e Questionário Morfossintático.

8 Os exemplos apresentados nas seis etapas de aquisição de fixidez foram extraídos do corpus deste estudo. 
Além disso, o Questionário Linguístico do ALiB contém perguntas que apuram fenômenos prosódicos; perguntas de pragmáticas; metalinguísticas e discursos semidirigidos e, ainda, um texto para leitura (COMITÊ NACIONAL..., 2001).

O Projeto ALiB, orientando pelos pressupostos da Geolinguística pluridimensional, reúne uma rede de pontos com 250 localidades e entrevistou 1.100 brasileiros. Para a seleção desses informantes considerou a naturalidade dos falantes, ou seja, todos deveriam ser nascidos nas localidades que integram a rede de pontos e serem filhos de pais também naturais da mesma região linguística. Além da dimensão diatópica, na seleção dos informantes foram considerados quatro veios sociolinguísticos (CARDOSO, 2010, p.49-51): variação diageracional (duas faixas etárias: 18-30 anos e 50-65 anos); variação diagenérica (sexos masculino e feminino); variação diastrática (escolaridade em nível fundamental; nas capitais foram também entrevistados informantes com formação universitária) e variação diafásica (resposta às perguntas dos questionários e às perguntas dirigidas (prosódia, pragmática, discurso semidirigidos), leitura de um texto). Obedecendo-se a esse perfil, foram entrevistados quatro informantes em cada uma das localidades do interior e oito nas 25 capitais brasileiras, exceção feita às capitais Brasília e Palmas que, em virtude de serem capitais recentes, ainda não possuem uma norma linguística definida9.

Como já assinalado, este trabalho analisa dados inéditos do Projeto ALiB que compõem o corpus do Projeto VALEXTRA que tem como objeto de investigação expressões fixas veiculadas na língua oral falada por brasileiros naturais das 26 Unidades da Federação do Brasil, documentadas pelo Projeto ALiB com o qual o Projeto VALEXTRA possui interfaces. O grande desafio que esse projeto se impôs foi o de identificar fraseologismos em um corpus que, além de ser de base oral, foi recolhido segundo a metodologia dos estudos geolinguísticos com as suas peculiaridades metodológicas, pois têm como propósito a produção de atlas linguísticos. O material linguístico, em pesquisas dessa natureza, é obtido com o auxílio de um questionário que tem finalidades bem específicas de acordo com o seu tipo (fonético-fonológico; semânticolexical e morfossintático) e com os objetivos da pesquisa dialetológica que tem como meta a produção de um atlas linguístico. A despeito dessas vicissitudes, $\mathrm{O}$ corpus do Projeto ALiB tem disponibilizado ao Projeto VALEXTRA dados

9 Cf. detalhamento da metodologia do ALiB no site do projeto: https://alib.ufba.br/content/metodologia. 
significativos, particularmente em algumas das 14 áreas semânticas que compõem o Questionário Semântico-Lexical, dentre elas a do corpo humano.

Para este trabalho, foram analisadas unidades lexicais fornecidas por 308 informantes naturais de 68 localidades das regiões Região Norte e Sul do Brasil (interior e capitais), 24 do Norte e 44 do Sul, ou seja: denominações fornecidas pelos 308 informantes entrevistados nessas duas regiões para perguntas do QSL - Questionário Semântico-Lexical, área semântica do corpo humano (32 perguntas), coletadas in loco pela equipe de pesquisadores do Projeto ALiB, classificadas como fraseologismos. Assim, para a análise dos dados, seguiramse os pressupostos teóricos da Fraseologia, vertente teórica francesa adotada pelo Projeto VALEXTRA ao qual este estudo se vincula, particularmente a concebida por Gross (1996) e por Mejri (1997).

$\mathrm{O}$ desenvolvimento deste trabalho obedeceu às seguintes etapas: i) levantamento de candidatos a expressões fixas do corpus do Projeto ALiB, inquéritos realizados nas localidades do interior das regiões Norte e Sul do Brasil, perguntas associadas à área semântica do corpo humano; ii) consulta a dicionários de língua portuguesa para verificar a dicionarização dos fraseologismos extraídos do corpus (HOUAISS, 2001; AULETE, 2014) e iii) análise dos fraseologismos do ponto de vista da motivação e da metáfora.

\section{EXPRESSÕES FIXAS DA ÁREA SEMÂNTICA CICLOS DA VIDA}

O levantamento dos dados demonstrou que 11 das 32 perguntas da área semântica do corpo humano (QSL/ALiB) produziram fraseologismos como resposta. Ao todo foram contabilizados 265 designativos no corpus estudado (respostas para as 32 perguntas selecionadas fornecidas pelos 308 informantes entrevistados nas duas regiões em exame), 214 unidades léxicas simples (81\%) e 51 unidades léxicas complexas (19\%).

O exame inicial do material catalogado demonstrou que nem todas as unidades complexas evidenciam fixidez total, ou seja, nem todas apresentam soldadura entre os elementos que as compõem. Muitas vezes, a fixidez ocorre em apenas uma parte da expressão, em só um elemento do sintagma, mas, mesmo assim, a unidade configura-se como expressão fixa, considerando a teoria de Gross (1996) e de Mejri (1997). As ocorrências com nenhum tipo de fixidez, caracterizando-se como combinatórias totalmente livres, não foram contabilizadas para o corpus deste estudo. Para tanto, foram examinadas as respostas registradas para as 32 perguntas do Questionário Semântico- 
Lexical/ALiB relacionadas à área semântica do corpo humano, e que constituem o corpus deste estudo, examinando as unidades lexicais candidatas a fraseologismos, com vistas a atestar a possível configuração dessas unidades lexicais complexas como expressões fixas. Essa etapa da análise seguiu os métodos propostos por Gross (1996), tendo-se confirmado um montante de 32 expressões fixas que são apresentadas no quadro 1.

Quadro 1 - Expressões fixas na área semântica do corpo humano registradas nas regiões Norte e Sul do Brasil (Projeto ALiB)

\begin{tabular}{|c|c|c|c|}
\hline $\begin{array}{c}\mathbf{N}^{\circ} \cdot \text { da } \\
\text { pergunta/ } \\
\text { QSL/ALiB }{ }^{10}\end{array}$ & Conceito & Região Norte & Região Sul \\
\hline 089 & $\begin{array}{l}\text { "A parte que cobre o } \\
\text { olho". }\end{array}$ & $\begin{array}{l}\text { capa do olho; capela do olho; } \\
\text { beira do olho }\end{array}$ & capa do olho; capela do olho \\
\hline 092 & $\begin{array}{l}\text { "A pessoa que tem } \\
\text { os olhos voltados } \\
\text { para direções } \\
\text { diferentes". }\end{array}$ & instalação trocada & \\
\hline 095 & $\begin{array}{l}\text { "A inflamação no } \\
\text { olho que faz com que } \\
\text { o olho fique } \\
\text { vermelho e } \\
\text { amanheça grudado". }\end{array}$ & remela de gato & \\
\hline 096 & $\begin{array}{l}\text { "Aquela pele branca } \\
\text { no olho que dá em } \\
\text { pessoas mais } \\
\text { idosas". }\end{array}$ & carne crescida & \\
\hline 098 & $\begin{array}{l}\text { "Os últimos dentes, } \\
\text { que nascem depois } \\
\text { de todos os outros, } \\
\text { em geral quando a } \\
\text { pessoa já é adulta". }\end{array}$ & dente do juízo & dente do juízo \\
\hline 105 & $\begin{array}{l}\text { "A parte alta do } \\
\text { pescoço do homem". }\end{array}$ & $\begin{array}{l}\text { fruto(a) do Adão; maçã de } \\
\text { Adão; pomo de Adão }\end{array}$ & $\begin{array}{l}\text { fruto(a) do Adão; maçã de } \\
\text { Adão; pomo de Adão; baga de } \\
\text { Adão; caroço de Adão; maçã } \\
\text { de Eva }\end{array}$ \\
\hline 109 & $\begin{array}{l}\text { "O mau cheiro } \\
\text { embaixo dos braços". }\end{array}$ & $\begin{array}{l}\text { catinga de porco; cheiro de } \\
\text { gambá; cheiro de porquinho; } \\
\text { fedor de caititu }\end{array}$ & $\begin{array}{l}\text { cheiro de asa; cheiro de } \\
\text { gambá; fedendo cebola }\end{array}$ \\
\hline 113 & $\begin{array}{l}\text { "A parte do corpo da } \\
\text { mãe onde fica o } \\
\text { bebê". }\end{array}$ & bolsa d'água & \\
\hline
\end{tabular}

10 Uma primeira análise dos fraseologismos catalogados como respostas para as perguntas 89, 92, 98, 105, 111, 116, 117 e 119 foi realizada por Nunes (2017), abordagem retomada e aprofundada para este artigo. 


\begin{tabular}{|c|l|l|l|}
\hline $\mathbf{1 1 6}$ & $\begin{array}{l}\text { "A pessoa de pernas } \\
\text { curvas". }\end{array}$ & $\begin{array}{l}\text { perna de alicate; perna de } \\
\text { arco; perna de baladeira; } \\
\text { perna de cambito; perna de } \\
\text { garrincha }\end{array}$ & $\begin{array}{l}\text { perna de alicate; perna de } \\
\text { zambeta }\end{array}$ \\
\hline $\mathbf{1 1 7}$ & $\begin{array}{l}\text { "O osso redondo que } \\
\text { fica na frente do } \\
\text { joelho". }\end{array}$ & $\begin{array}{l}\text { bolacha do joelho; pratinho } \\
\text { do joelho; roda do joelho }\end{array}$ & $\begin{array}{l}\text { tampa do joelho; tramela do } \\
\text { joelho }\end{array}$ \\
\hline $\mathbf{1 1 9}$ & $\begin{array}{l}\text { "A parte posterior, } \\
\text { arredondada, do pé } \\
\text { humano, abaixo do } \\
\text { tornozelo e atrás do } \\
\text { arco do pé". }\end{array}$ & calcanhar de Aquiles & \\
\hline
\end{tabular}

Fonte: Elaborado pelas autoras.

Levantadas as unidades léxicas candidatas a expressões fixas, foram consultadas obras lexicográficas e outras fontes necessárias para elucidação dos fraseologismos. Na sequência, são analisados os itens fraseológicos elencados no quadro 1. Para tanto obedeceu-se à sequência cronológica das perguntas do Questionário Semântico-Lexical do Projeto ALiB e seguida na organização do corpus no quadro 1.

\section{A "a parte que cobre o olho" (QSL 089)}

Beira do olho

Capa do olho

Capela do olho

(substantivo + preposição + artigo + substantivo)

Essas denominações são utilizadas para nomear a parte acima do olho, na linguagem especializada denominada como pálpebra. Os três itens léxicos são formados pela mesma estrutura morfológica. Beira, capa e capela pertencem ao mesmo paradigma semântico, caracterizado pela ação de cobrir algo. Em específico, contemporaneamente, a unidade léxica capela nomeia uma pequena igreja com apenas um altar. Todavia, segundo Machado (1987), capela vem do latim capella, diminutivo de capa. A ocorrência de capela do olho pode recuperar o sentido original da palavra e resulta da analogia estabelecida entre as características da pálpebra e da "capa" pequena" ${ }^{11}$ Capela do olho aparece no verbete original no dicionário Aulete Digital (AULETE, 2014), como uma das acepções de capela, o que denota não se tratar de uso contemporâneo desse fraseologismo. Segundo a classificação de Gross (1996), a expressão apresenta fixidez parcial de um elemento nominal, no caso, capela. Para Mejri (1997), trata-

11 A esse respeito confira o estudo de Isquerdo (2003). 
se de uma sequência fixa com sentido que pode ser deduzível a partir dos elementos que integram a expressão.

B "a pessoa que tem os olhos voltados para direções diferentes" (QSL 092)

$$
\begin{aligned}
& \text { Instalação trocada } \\
& \text { (substantivo + verbo/função adjetiva) }
\end{aligned}
$$

A sequência fixa instalação trocada apresenta uma fixidez completa (GROSS, 1996) e é uma sequência fixa deduzível a partir do contexto (MEJRI, 1997). A característica anatômica do estrábico é explicada pela falta de paralelismo entre os eixos visuais, de modo que instalação trocada remete a essa falta de simetria. A origem da expressão é metafórica e parece mostrar a similaridade entre a anatomia física do estrábico e o conceito por ela expressado $^{12}$.

C "A inflamação no olho que faz com que o olho fique vermelho e amanheça grudado" (QSL 095)

$$
\begin{aligned}
& \text { Remela de gato } \\
& \text { (substantivo + preposição + artigo + substantivo) }
\end{aligned}
$$

A expressão remela de gato para denominar "a inflamação que faz com que o olho fique vermelho e amanheça grudado", também metafórica, tem origem na secreção, geralmente amarelada que se acumula nas bordas das pálpebras e que é similar àquela que aparece nos olhos dos gatos em consequência de alergias ou mudança de estação. Observa-se uma fixidez parcial, que ocorre no sintagma de gato (GROSS, 1996) e pode ser deduzível a partir dos elementos que integram a expressão. Quem tem ou conhece bem os felinos domésticos consegue estabelecer a relação analógica entre a secreção ocular humana, denominada remela, e a secreção ocular do felino que faz com que os olhos do gato fiquem grudados.

\section{$D$ “Aquela pele branca no olho que dá em pessoas mais idosas" (QSL 096) \\ Carne crescida \\ (substantivo +verbo/particípio)}

12 Cf. estudos sobre denominações para “vesgo" realizados por Nunes e Isquerdo (2012; 2017). 
A expressão carne crescida é, geralmente, usada para nomear o pterígio, formação carnosa que avança sobre a córnea, geralmente do lado nasal, como resposta do olho a um processo de irritação ocular. Desse modo, é a própria aparência de carne em tamanho aumentado da região ocular afetada que motiva o uso da expressão. Entretanto, neste caso, o referente do fraseologismo não é a catarata, uma das possíveis respostas esperada para a pergunta, o que não compromete o caráter fraseológico da expressão, apenas aponta-lhe conceito diverso do expresso na pergunta do QSL/ALiB.

\section{E “Últimos dentes, que nascem depois de todos os outros, em geral quando a pessoa já é adulta" (QSL 098)}

Dente do juízo

(substantivo + preposição + artigo + substantivo)

O dente do juízo é conhecido por ser o dente que nasce por último, quando a pessoa já está na fase adulta da vida. Na cultura popular, o dente do siso foi denominado como dente do juízo porque é corrente dizer que quando nascem os últimos dentes, a pessoa cria juízo (discernimento). Em outras palavras, coincidindo com o nascimento dos últimos dentes, a pessoa adquire a capacidade de avaliar e discernir as coisas, de modo que, popularmente, os dentes do siso são denominados, também, como os dentes do juízo. Esse fraseologismo apresenta uma fixidez parcial que recai no item lexical do juízo (GROSS, 1996). É uma sequência fixa que tem o sentido composicional (MEJRI, 1997).

\section{F "parte alta do pescoço do homem" (QSL 105)}

Baga de Adão

Caroço de Adão

Fruto(a) de Adão

Gogó de Adão

Maçã de Adão

Maçã de Eva

Pomo de Adão

(substantivo + preposição + substantivo)

Todas as expressões fixas encontradas no corpus para nomear "a parte alta do pescoço do homem" são conhecidas por sua origem bíblica, com explicação na história do pecado original, logo no início do mundo, que é 
narrada pelo livro do Gênesis. Essas expressões possuem, portanto, cunho mitológico e religioso e estão fundamentadas na narrativa bíblica segundo a qual, estando no paraíso, Adão e Eva encontram-se com a serpente que instiga Eva a comer o fruto proibido, representado no imaginário coletivo como uma maçã. Eva oferece a maçã a Adão e os dois, após comerem o fruto proibido, são expulsos do Jardim do Éden. Com efeito, quando Adão come a maçã, parte da fruta fica presa na região da garganta, o que, conforme o imaginário popular, deu origem ao gogó masculino, também denominado, gogó de Adão. É uma sequência fixa com sentido não deduzível pelos elementos, apenas pelo contexto (MEJRI, 1997). Tem fixidez completa (GROSS, 1996), com sentido não deduzível de seus elementos constituintes, mostrando-se totalmente opaco.

\section{G “O mau cheiro embaixo dos braços" (QSL/109)}

Catinga de porco

Cheiro de asa

Cheiro de gambá

Cheiro de porquinho

Fedor de caititu

Fedor de cebola

(substantivo + preposição + substantivo)

No grupo de expressões fixas encontradas nas respostas fornecidas pelos informantes do Projeto ALiB para nomear o "mal cheiro embaixo dos braços", chama a atenção a presença de zoomorfismos que estabelecem a analogia entre o odor humano, expresso pelos itens cheiro (mais neutro), catinga e fedor (mal cheiro), e o cheiro de animais cuja característica principal é o odor desagradável, como o porco, o gambá e o caititu. As expressões catinga de porco e fedor de caititu são, semanticamente, redundantes já que catinga e fedor significam 'mal cheiro', como é possível verificar na primeira acepção atribuída a esses itens lexicais no Dicionário Aulete Digital (AULETE, 2014). No mesmo paradigma do zoomorfismo, a expressão cheiro de asa parece advir da metonímia parte pelo todo, em que asa (cada um dos membros anteriores das aves que, geralmente, serve para voar) faz alusão ao braço, mais especificamente, à parte inferior que o liga ao corpo, lugar onde, por falta de higiene ou do uso de desodorante, ocorre o mal cheiro humano. Outro elemento usado na constituição de expressão fixa para nomear o "mal cheiro embaixo do braço" é a cebola, em razão, talvez, do seu cheiro forte, nem sempre apreciado 
pelas pessoas. Tratam-se de expressões que apresentam fixidez parcial (GROSS, 1996), cujo sentido abstrato pode ser deduzível a partir dos elementos que a integram.

\section{$H$ "a parte do corpo da mulher onde fica o nenê/bebê antes de nascer" (QSL 111)}

Bolsa d'água

(Substantivo + preposição + substantivo)

Bolsa d'água é uma expressão fixa justificada pela própria anatomia do útero que, na gravidez, adota a forma de uma bolsa com conteúdo líquido, o líquido amniótico. Este cumpre um papel importante para o crescimento do bebê, pois permite que o feto faça seus primeiros movimentos, sem os quais o bebê não desenvolveria os ossos e músculos. Aos nove meses de gestão, é comum ouvir "a bolsa estourou", em razão do líquido amniótico que, inesperadamente, sai em grande quantidade, alertando à mulher que chegou a hora do bebê nascer. Essa expressão tem fixidez parcial (GROSS, 1996) e é uma sequência fixa, deduzível pelos elementos que a compõem (MEJRI, 1997).

\section{I "pessoa de pernas curvas" (QSL 116)}

Perna de alicate

Perna de arco

Perna de baladeira

Perna de cambito

Perna de garrincha

Perna de zambeta

(substantivo + preposição + substantivo)

Essas expressões fixas são discutidas em bloco por serem resultado de um mesmo processo metafórico com a finalidade de nomear o referente "pernas curvas". A variante lexical perna de alicate é constituída a partir da analogia entre o formato da perna e o do alicate, instrumento utilizado para cortar e que tem as hastes curvas. Fenômeno similar ocorre com perna de arco e perna de cambito $^{13}$, em razão do formato curvo do arco e do cambito cujos nomes integram a expressão fixa para nomear pernas curvas. Já perna de baladeira é uma

13 O Dicionário Aulete Digital (AULETE, 2014) define cambito, em sua terceira acepção, como "Forquilha dupla de madeira, em forma de $V$, que se prende de cada lado do lombo das bestas de carga". 
analogia ao estilingue, brinquedo formado por hastes de couro e uma forquilha, também curva, utilizado para matar passarinhos. Baladeira é como se chama esse brinquedo na região Norte do Brasil, conforme pode ser verificado nas cartas linguísticas sobre as denominações de estilingue que integram o volume 2 do ALiB: L19, L19a, L19b, L19c. L19d e L19e (CARDOSO et al, 2014). Perna de garrincha faz alusão ao jogador de futebol brasileiro Manuel Francisco dos Santos, apelidado de Mané Garrincha ou simplesmente Garrincha, que possuía as pernas curvas. Por analogia a essa característica da anatomia das pernas do futebolista, as pernas curvas passaram a receber, também, em certas localidades do país, o nome de perna de garrincha. Por sua vez, o item zambeta, no Dicionário Aulete Digital, remete a cambaio e a zambo. Cambaio, em sua primeira acepção significa "que tem pernas tortas" (AULETE, 2014). Desse modo, a expressão fixa perna de zambeta acaba se comportando como um pleonasmo, uma vez que, em nível conceitual, verifica-se uma redundância do termo. Neste caso, estaríamos diante de uma expressão com sentido totalmente composicional, ou seja, uma sequência livre (MEJRI, 1997).

A análise mostra que as cinco expressões fixas revelam uma fixidez de uma parte do grupo nominal (GROSS, 1996), aquele que emerge das relações metafóricas, e são sequências fixas de sentido deduzível a partir dos elementos e do contexto (MEJRI, 1997).

\section{$\mathrm{J}$ "osso redondo que fica na frente do joelho" (QSL 117)}

Bolacha do joelho

Pratinho do joelho

Tampa do joelho

Tramela do joelho

Roda do joelho

(substantivo + preposição + artigo + substantivo)

O item lexical bolacha do joelho, terceiro mais produtivo no universo pesquisado, é utilizado para nomear o osso que se encontra na frente do joelho, que recebe o nome técnico de rótula. Essa variante também resulta de um mecanismo metafórico, uma vez que a rótula tem o formato arredondado, como o de uma bolacha. Processo similar ao que ocorre com as expressões pratinho do joelho, tampa do joelho e roda do joelho. Portanto, os informantes de acordo com os objetos mais comuns em sua vivência, utilizam os designativos bolacha, pratinho, tampo e roda para nomear o "osso redondo que fica na frente do joelho". A 
mesma explicação pode subsidiar a análise de tramela do joelho, também resultante de um fenômeno metafórico, já que a tramela, tipo de trava da porta que apresenta forma retangular, acaba funcionando como elemento que oferece parâmetros de comparação para o referido osso do joelho.

Considera-se essa unidade com um grau de fixidez parcial com só uma parte do grupo nominal (GROSS, 1996), é uma sequência fixa de sentido deduzível a partir dos elementos e do contexto (MEJRI, 1997).

\section{K “A parte posterior, arredondada, do pé humano, abaixo do} tornozelo e atrás do arco do pé" (QSL 119)

Calcanhar de Aquiles

(substantivo + preposição + substantivo)

Essa expressão é oriunda da mitologia grega, segundo a qual, quando Aquiles nasceu, sua mãe, Tetis, o mergulhou no rio Estige e o tornou imortal. Contudo, só havia uma * parte do corpo vulnerável em Aquiles, a parte em que sua mãe o segurou para emergi-lo no rio, o calcanhar. Embora o referente do fraseologismo não seja o calcanhar, uma das respostas esperadas para a questão, não se pode desprezar o caráter fraseológico da ocorrência, já que apenas aponta um conceito diverso do expresso na pergunta do QSL/ALiB. O uso do fraseologismo, de sentido totalmente metafórico, serve para indicar o ponto fraco de uma pessoa. Segundo a teoria que fundamenta este trabalho, trata-se de um caso de fixidez total (GROSS, 1996) e uma sequência fixa com sentido deduzível a partir dos elementos e do contexto (MEJRI, 1997).

Para concluir a discussão dos dados apresenta-se outra possibilidade de abordagem das unidades lexicais complexas oriundas de um corpus de natureza geolinguística. Trata-se do mapeamento das expressões fixas relacionadas ao conceito expresso na pergunta 105 ("A parte alta do pescoço do homem"), com vistas a verificar a distribuição espacial desses fatos lexicais.

Assim, as figuras 2 e 3 trazem as cartas que documentam fraseologismos registrados nas capitais brasileiras que integram a rede de pontos do ALiB, respectivamente, nas regiões Norte e Sul do Brasil.

A figura 2, por seu turno, traz a distribuição dos dois fraseologismos apurados nas capitais da Região Norte: pomo de Adão e gogó de Adão. A carta demonstra que pomo de Adão é praticamente forma categórica nessa região, pois teve $100 \%$ de ocorrências em cinco das seis capitais que integram a rede, ao contrário de gogó de Adão que só foi obtido em Porto Velho. Já a figura 3 contém 
a distribuição diatópica das quatro expressões fixas coletadas nas capitais da Região Sul para nomear o mesmo conceito: baga de Adão; pomo de Adão; caroço de Adão e maçã de Adão. Os dados demonstram que apenas o fraseologismo pomo de Adão, auferido em Porto Alegre e em Curitiba, aproxima as duas regiões brasileiras aqui focalizadas. Os outros três foram documentados em apenas uma das capitais: baga de Adão, única unidade fraseológica recolhida em Florianópolis; caroço de Adão que divide espaço com pomo de Adão em Curitiba e maçã de Adão só mencionada em Porto Alegre, também disputando espaço com pomo de Adão.

Ressalte-se que esse viés de análise poderia ser aplicado a todas as perguntas do QSL/ALiB, tanto a dados das capitais quanto do interior, tendo em vista a natureza geolinguística do corpus. Todavia, em razão dos limites deste trabalho, apresenta-se o mapeamento das respostas obtidas para a pergunta 105 do QSL/ALiB, dados relativos às capitais brasileiras, com vistas a demonstrar a distribuição diatópica dos fraseologismos a ela relacionados. Trata-se de outra possibilidade de análise desse tipo de dado lexical.

Figura 2 - Expressões fixas que nomeiam o "pomo de Adão" nas capitais da Região Norte do Brasil

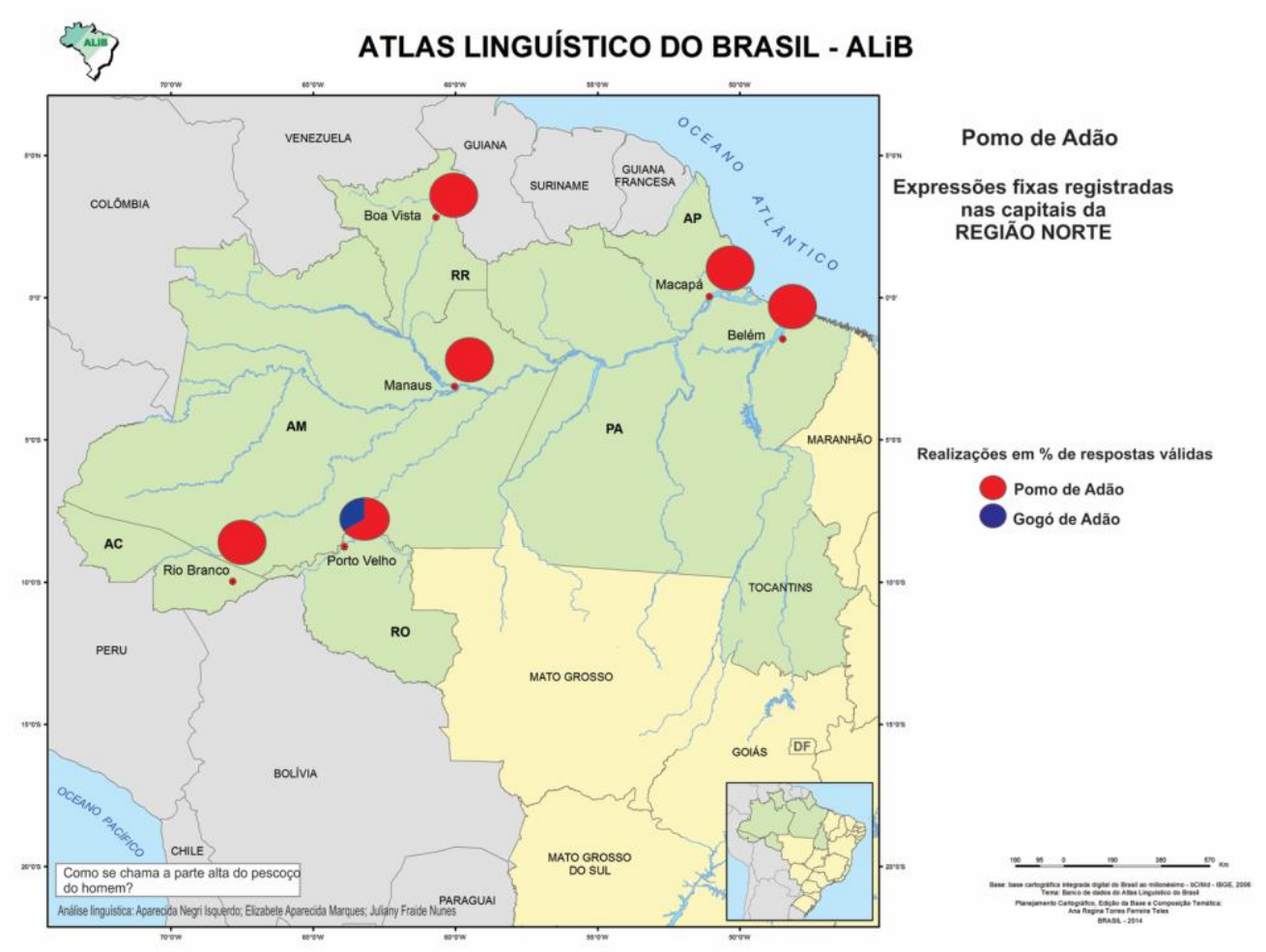


Figura 3 - Expressões fixas que nomeiam o "pomo de Adão" nas capitais da Região Sul do Brasil

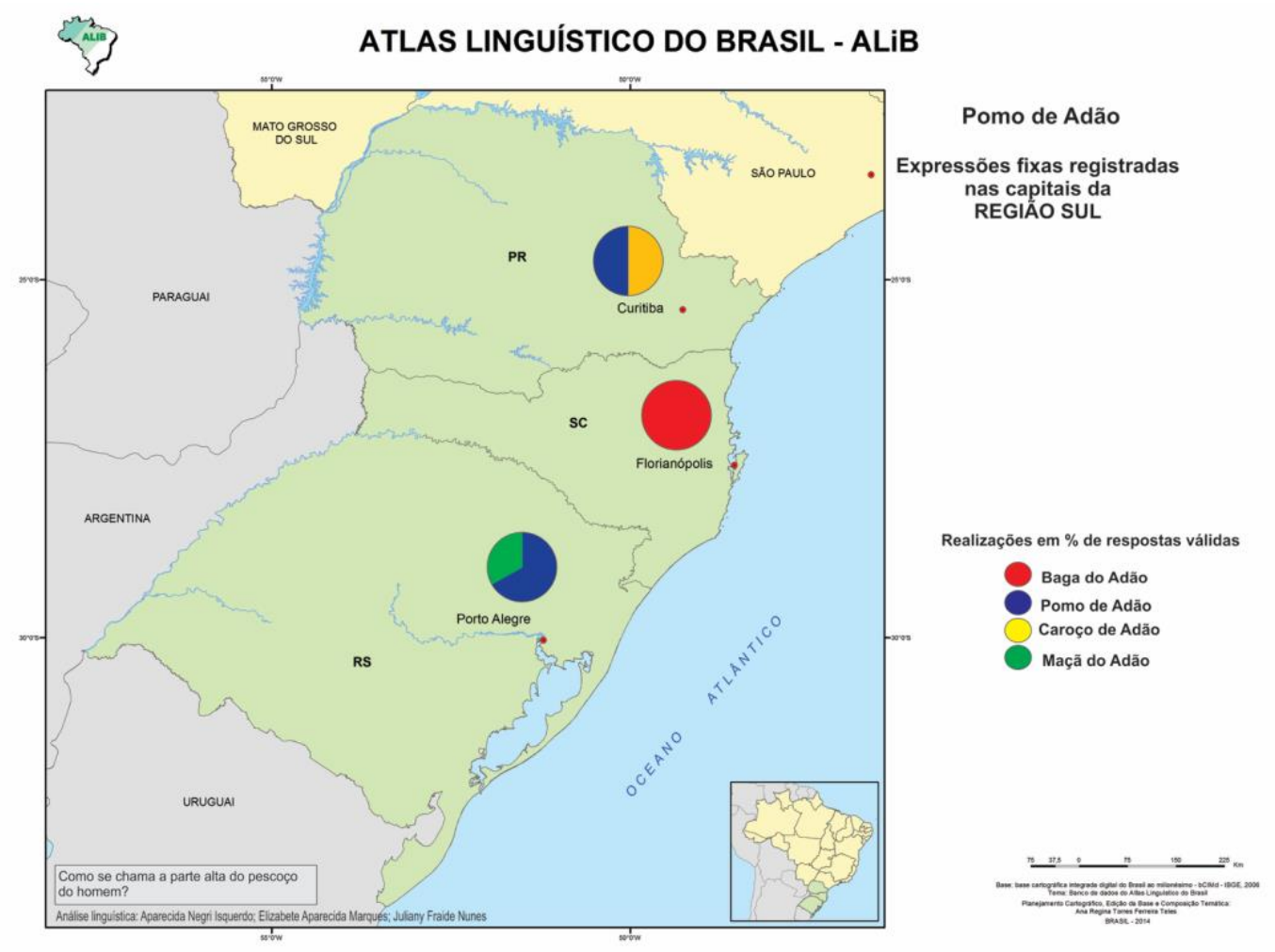

\section{CONSIDERAÇÕES FINAIS}

O material linguístico examinado neste artigo demonstra como o léxico de uma língua evidencia aspectos da identidade de seus falantes, à medida que condicionantes sociais e culturais da comunidade linguística se refletem nas escolhas lexicais dos habitantes de uma região geográfica, razão pela qual, dadas as suas particularidades, pode subsidiar estudos sob diferentes eixos. Neste texto, dados lexicais de cunho geolinguístico que, embora tenham sido recolhidos com base em metodologia específica e particular dessa área de conhecimento, favoreceram um estudo de natureza fraseológica.

As expressões fixas analisadas deram mostras da vitalidade desse tipo de unidade lexical na área semântica do corpo humano em localidades do interior e em capitais das regiões Norte e Sul do Brasil. Além da produtividade na fala dos 308 brasileiros entrevistados nessas duas áreas geográficas, os fraseologismos estudados evidenciaram mecanismos de formação desse tipo de unidade lexical, em especial, o metafórico, pois demonstraram que o falante 
utiliza processos distintos para nomear partes do corpo humano que evocam esferas particulares de motivação.

Em síntese, o estudo demonstrou a importância dos estudos fraseológicos a partir de dados orais e a relevância dos resultados para a construção do saber linguístico e para o conhecimento do léxico do português brasileiro. Expressões fixas como capela do olho (pálpebra), instalação trocada (vesgo), cheiro de asa (odor das axilas), perna de alicate (perna torta), tramela de joelho (rótula), calcanhar de Aquiles (calcanhar) povoam o falar cotidiano de nortistas e sulistas razão pela qual unidades léxicas complexas oriundas do discurso oral continuam a instigar estudos na área da Fraseologia, pois demonstram a relação entre fraseologismo e discurso como já pontuado por Mortureux (2011).

\section{REFERÊNCIAS}

BIDERMAN, Maria Tereza Camargo. Conceito linguístico da palavra. In: Revista Palavra/ Departamento de Letras da PUC-Rio. Rio de Janeiro, Grypho, 1999, p. 81-97.

CARDOSO, Suzana Alice Marcelino. Geolinguística: Tradição e Modernidade. São Paulo: Parábola, 2010.

CARDOSO, Suzana Alice Marcelino et al. Atlas linguístico do Brasil: volume 2. Londrina: Eduel, 2014.

COMITÊ NACIONAL DO PROJETO ALIB. Atlas linguístico do Brasil: questionário 2001. Londrina: Eduel, 2001.

CORPAS PASTOR, Gloria. Manual de fraseología española. Madrid: Gredos, 1996.

DICIONÁRIO CALDAS AULETE: Dicionário Aulete digital. Lexicon Editora Digital, 2014. Disponível em http://www.aulete.com.br, acesso em 08/07/2018.

GONZÁLEZ REY, Isabel. La phraséologie du français. Toulouse: Presses Universitaires du Midi, 2015.

GROSS, Gaston. Les expressions figées em français: noms composés et autres locutions. Paris: Ophrys, 1996.

HOUAISS, Antônio. Dicionário Eletrônico Houaiss da Língua Portuguesa, Versão 1.0. Rio de Janeiro: Editora Objetiva, 2001.

ISQUERDO, Aparecida Negri. Léxico em tempo e espaço: a questão dos regionalismos. In: MARIN, Jérri Roberto; VASCONCELOS, Cláudio Alves de. (Orgs.) História, região e identidades. Campo Grande/MS: Editora da UFMS, 2003, p. 165-181.

MACHADO, José Pedro. Dicionário etimológico da língua portuguesa. Segundo volume (C-E). Lisboa: Livros Horizonte, 1987. 
MARQUES, Elizabete Aparecida. Expressões idiomáticas do espanhol e do português formadas por lexias que designam partes do corpo humano: um estudo cognitivo a partir de dados lexicográficos. In: ISQUERDO, Aparecida Negri; SEABRA, Maria Cândida Trindade Costa de (Orgs.). As ciências do léxico: lexicologia, lexicografia e terminologia. Vol. VI. Campo grande, MS: Ed. UFMS, 2012, p. 333-351.

MEJRI, Salah. Le figement lexical. Tunis: Publications de la Faculté des Lettres de la Manouba, 1997.

MORTUREUX, Marie-Françoise. La lexicologie entre langue et discours. 2a ed. Paris: Armand Colin, 2011.

NUNES, Juliany Fraide; ISQUERDO, Aparecida Negri. Unidades fraseológicas na língua falada da região Norte do Brasil: um estudo a partir dos dados do Projeto ALiB. Comunicação apresentada no IV Congresso Internacional de Fraseologia e Paremiologia e [do] III Congresso Brasileiro de Fraseologia, realizado na UNESP/São José do Rio Preto/SP, em março de 2016.

NUNES, Juliany Fraide; ISQUERDO, Aparecida Negri. Variantes para vesgo nas capitais das regiões Centro-Oeste e Norte: contribuições do ALiB. In: ISQUERDO, Aparecida Negri; ALTINO, Fabiane Cristina; AGUILERA, Vanderci de Andrade. Atlas Linguístico do Brasil: Descrevendo a língua, formando jovens pesquisadores... Londrina-PR: EDUEL, 2012.

NUNES, Juliany Fraide; ISQUERDO, Aparecida Negri. Vesgo, zarolho ou estrábico? O que dizem os dados do ALiB das regiões Norte e Sul do Brasil. Revista galega de filoloxía. Monografía 11. GRANJA, María Álvarez de la; AGRELO, Ana Boullón; SEOANE, Ernesto Gonzáles. Aproximacións á variación lexical no domínio galego-portugués. Santiago de Compostela, 2017, p. 69-88.

NUNES, Juliany Fraide. Vocabulário do corpo humano nas regiões Norte e Sul do Brasil: perspectivas semântica e geossociolinguística. 2017. 256 p. Dissertação (Mestrado em Estudos de Linguagem) - Universidade Federal de Mato Grosso do Sul, Campo Grande/MS, 2017.

PENADÉS MARTÍNEZ, Inmaculada. La teoría cognitiva de la metonimia a la luz de locuciones nominales somáticas. Revista española de lingüística, n 40, fasc. 2, 2010, p. 7594.

POTTIER, Bernard. Presentación de la Linguistica: fundamentos de una teoria. Traducción de Antonio Quilis. Madrid: Ediciones Alcalá, 1968.

Real Academia Española. Diccionario de la lengua española (22.a ed.), 2001. Disponível em http://www.rae.es/rae.html, acesso em 10/07/2018.

TRISTÁ, Antonia Maria. Fraseología y contexto. La Habana: Ciencias Sociales, 1988.

Nota do editor:

Artigo submetido para avaliação em: 08 de agosto de 2018.

Aprovado em sistema duplo cego em: 27 de setembro de 2018. 